University of Nebraska - Lincoln

DigitalCommons@University of Nebraska - Lincoln

Social Integration and Domestic Violence Support in an Indigenous Community: Women's Recommendations of Formal Versus Informal Sources of Support

G. Robin Gauthier

Sara C. Francisco

Bilal Khan

Kirk Dombrowski

Follow this and additional works at: https://digitalcommons.unl.edu/sociologyfacpub

Part of the Family, Life Course, and Society Commons, and the Social Psychology and Interaction Commons

This Article is brought to you for free and open access by the Sociology, Department of at DigitalCommons@University of Nebraska - Lincoln. It has been accepted for inclusion in Sociology Department, Faculty Publications by an authorized administrator of DigitalCommons@University of Nebraska - Lincoln. 


\title{
Social Integration and Domestic Violence Support in an Indigenous Community: Women's Recommendations of Formal Versus Informal Sources of Support
}

\author{
G. Robin Gauthier, ${ }^{1}$ Sara C. Francisco, ${ }^{2}$ \\ Bilal Khan, ${ }^{1}$ and Kirk Dombrowski ${ }^{1}$ \\ 1 University of Nebraska-Lincoln \\ 2 Pennsylvania State University, University Park \\ Corresponding author - G. Robin Gauthier, Department of Sociology, \\ University of Nebraska-Lincoln, 719 Oldfather Hall Lincoln, NE 68588, USA. \\ Email: ggauthier3@unl.edu \\ ORCID iD G. Robin Gauthier https://orcid.org/0000-0002-7472-2597
}

\begin{abstract}
Throughout North America, indigenous women experience higher rates of intimate partner violence and sexual violence than any other ethnic group, and so it is of particular importance to understand sources of support for Native American women. In this article, we use social network analysis to study the relationship between social integration and women's access to domestic violence support by examining the recommendations they would give to another woman in need. We ask two main questions: First, are less integrated women more likely to make no recommendation at all when compared with more socially integrated women? Second, are less integrated women more likely than more integrated women to nominate a formal source of support rather than an informal one? We use network data collected from interviews with 158 Canadian women residing in an indigenous
\end{abstract}

Published in Journal of Interpersonal Violence 36:7-8 (2021), pp 3117-3141

DOI: $10.1177 / 0886260518768567$

Copyright (C) 2018 G. Robin Gauthier, Sara C. Francisco, Bilal Khan, and Kirk Dombrowski.

Published by SAGE Publications. Used by permission. 
community to measure their access to support. We find that, in general, less integrated women are less likely to make a recommendation than more integrated women. However, when they do make a recommendation, less integrated women are more likely to recommend a formal source of support than women who are more integrated. These results add to our understanding of how access to two types of domestic violence support is embedded in the larger set of social relations of an indigenous community.

Keywords: domestic violence, rural women, social support

\section{Introduction}

Throughout North America, indigenous women experience higher rates of intimate partner violence (IPV) and sexual violence than any other ethnic group (Bryant-Davis, Chung, \& Tillman, 2009; Greenfield \& Smith, 1999; Hamby, 2000; Tjaden \& Thoennes, 2000; Yuan, Koss, Polacca, \& Goldman, 2006). Domestic violence (DV) within indigenous communities is rooted within several causes, including the demographic profile typical of Native American, First Nation, and Inuit communities (Brownridge, 2008). Many indigenous communities have high rates of poverty, alcohol and drug abuse, and problems associated with rural isolation (Jones, 2008). Furthermore, historical trauma and culture loss are population-specific risk factors for indigenous DV that follow from the experience of colonization (Chester, Robin, Koss, Lopez, \& Goldman, 1994; McEachern, Van Winkle, \& Steiner, 1998). It is, therefore, of particular importance to understand sources of support for Native American women living within Native American communities. In this article, we examine the types of DV support Canadian women residing in an indigenous community would recommend to another woman in need.

Past examinations of DV support distinguish between formal (or institutional) and informal (or social) sources. Formal support includes resources women can access from doctors, police, or social services. Informal support includes access to information and resources, which, in turn, can contribute to help-seeking behavior (Berkman, Glass, Brissette, \& Seeman, 2000). Informal support is accessed through relationships with relatives, friends, neighbors, coworkers, and so on (Belknap, Melton, Denney, Fleury-Steiner, \& Sullivan, 2009; Ruback \& Jasmin, 1994). 
We draw on a social network approach to measure the relationships that provide women with potential access to informal support. The application of network methods to measure informal support has become increasingly mainstream in the social sciences. The approach emphasizes the social dependencies among individuals when attempting to understand a wide range of substantive outcomes (Luke \& Harris, 2007). An individual's social context can magnify risk (Merli, Moody, Mendelsohn, \& Gauthier, 2015) or reduce it by providing the individual with access to informal support (Goldsmith \& Albrecht, 2011) above and beyond individual characteristics, behaviors, and risk factors. Informal support is one of the key mechanisms through which social integration influences health-related outcomes. We draw on a network approach to understand how relationships facilitate women's access to people and institutions who could provide support and to material and traditional resources to assist women experiencing DV.

We offer two concrete hypotheses. The first focuses on isolation as a key predictor of support resources (Hypothesis 1 [H1]): Women who participate in fewer exchanges may suffer social isolation and thus be more likely to be unable to make any recommendation to a woman experiencing DV at all. Second, we offer a substitution hypothesis (Hypothesis 2 [H2]): Women who participate in fewer exchanges may have less access to informal support and thus may be more likely to substitute informal recommendations for formal ones.

We draw on a context-rich community-wide resource sharing dataset from an indigenous community in the Canadian Arctic. The data used in this analysis were collected through hour-long semi-structured interviews with 158 women living within the community. They were asked as follows: "If a woman was in need who would you send her to?" Their responses referred to specific people and institutions within the community. Interviewees also provided extensive information about their social exchanges across a range of material, social, and cultural domains. Throughout this article, the extent of women's potential access to informal support is measured using their participation in six exchanges across three conceptual categories: potential companionship (alcohol co-use), material support (housing assistance, jobs assistance, and store food assistance), and traditional support (traditional knowledge and country food ${ }^{1}$ ). In what follows, we present a discussion of both the general risk factors and historically specific 
ones that contribute to DV in indigenous communities, and provide tests for the two hypotheses above within companionship, traditional, and material domains.

\section{Background Literature}

Formal and informal support. Women may prefer to recommend informal support when they can because they are more flexible and less constrained in the assistance they can provide relative to formal sources of support. Furthermore, women may be reluctant to make use of formal supports when this may risk upsetting existing social relations. Conversely, informal support can be accessed within locally accepted social channels (creating less social rupture) and women are more likely to utilize informal sources and to find those sources most supportive (Bosch \& Bergen, 2006). In their study of Canadian women reporting IPV, Kaukinen, Meyer, and Akers (2013) found that $69 \%$ sought help from a family member or friend and only $22 \%$ of women who reported physical violence reported the abuse to police. Women who do seek help from the police have frequently reported being treated in nonsupportive ways (Grossman, Hinkley, Kawalski, \& Margrave, 2005; Mitchell \& Hodson, 1983; Stark \& Flitcraft, 1996; Tan, Basta, Sullivan, \& Davidson, 1995; Websdale, 1998). Police response has been criticized as delayed, or lacking, and when the perpetrators are punished, the punishments have been criticized as too lenient (Burnette, 2015; Trujillo \& Ross, 2008). The small community setting of Native American communities can exasperate the situation. Smaller, tightly connected communities generally have fewer resources at their disposal (Bosch \& Schumm, 2004; Jones, 2008) and problems with confidentiality (Burnette, 2015).

Potential sources of informal support: Material, companionship, and traditional exchanges

Material support. Rural women are known to be at higher risk of DV than women in urban areas, and the abuse tends to be longer lasting (Thurston, 1996; Websdale, 1995). Several factors make it more difficult for rural women suffering from DV to seek support and to leave 
the abusive relationship. Indigenous communities are frequently located in remote, rural locations which often lack access to support services and jobs. High unemployment is a stressor that has been linked to gendered conflict in Native American communities. Men who have lost their livelihoods with their land are under a great deal of stress, when jobs are scarce (Dombrowski, 2007; Whitbeck, Chen, Hoyt, \& Adams, 2004) and women face their partners' potential resentment if they are fortunate enough to find employment if their partners are not (Seale, Shellenberger, \& Spence, 2006). If a woman experiencing DV does decide to leave the relationship, a lack of affordable housing, in conjunction with geographic and social isolation in rural areas, increases her risk for unstable housing (Anderson, Renner, \& Bloom, 2014; Moffitt, Fikowski, Mauricio, \& Mackenzie, 2013). Some of the negative effects of living in a rural area might be reduced through women's participation in informal networks of material assistance, including access to jobs, housing, and food. Specifically, women who report receiving this help may also be in a better position to nominate someone who could effectively support a woman experiencing DV.

Companionship. The prevalence of alcohol use within Native American communities presents a contextually specific challenge (Wood \& Gruenewald, 2006). Specifically, alcohol use has been linked to the Native American experience of assimilation policies (Whitbeck et al., 2004) and a powerful sense of historical loss (Seale et al., 2006). Qualitative work suggests that the binge alcohol abuse within Native American communities cannot be understood outside this historical context (Jones, 2008; Matamonasa-Bennet, 2014; Seale et al., 2006). Women's alcohol use is likely to have an ambiguous relationship with informal support. On one hand, there is a small positive relationship between drinking and DV among women, although the effect size is smaller than among men (Foran \& O'Leary, 2008), and social isolation is often part of DV itself (El-Bassel, Gilbert, Rajah, Folleno, \& Frye, 2001). On the other hand, women who have alcohol co-use partners may have more access to informal support than women who have none. To the extent that alcohol co-use provides a common context for social connections (i.e., "drinking buddies"; Leonard, Kearns, \& Mudar, 2000), these relationships may provide the emotional support women experiencing DV need. 
Traditional cultural sources of support. Informal relationships that allow women to access traditional cultural resources may offer a contextually unique type of assistance that can influence their help-seeking strategies, or even provide direct help via social sanction and locally acceptable forms of leaving the abusive relationship. Recent research has explored how colonization has contributed to IPV through a series of policies directed at eradicating Native American's self-determination (Bubar \& Thurman, 2004; Whitbeck et al., 2004). Forced relocation, and residential schools physically separated kin groups, producing intergenerational patterns of social isolation and marginality even within indigenous communities (Dombrowski, Khan, Moses, Channell \& Dombrowski, 2014). Women were cut off from traditional means of support from their kin and natal communities (Bubar \& Thurman, 2004). Outlawing traditional religion and enforcing children's enculturation within residential schools limited Native Americans' ability to transmit their culture across generations, resulting in cultural loss. Participation in networks of kinship, traditional knowledge, and exchanges of locally fished, hunted, or collected foodstuffs which is locally referred to as "country food" (Dombrowski, Channell, Khan, Moses \& Misshula, 2013) directly address the cultural loss and historical trauma that have contributed to high rates of DV in Native American communities (Kirmayer, 2004).

Nomination patterns: Isolation and substitution. Women who are less integrated into material, emotional, and traditional support networks may not feel supported enough to seek either formal or informal sources of support and may make no nomination as a result. Such a finding would support the isolation hypothesis (H1). Alternatively, women who are integrated into material, emotional, and traditional support networks may have less need to turn to formal sources of support while women who are less integrated into these same networks may turn to formal sources, providing evidence for the substitution hypothesis (H2).

Previous empirical evidence provides support for both the isolation hypothesis and the substitution hypothesis. Isolated women are less likely to be able to access any form of supports. Bosch and Schumm (2004) reported that women with higher income and stronger social support networks in rural communities had access to a greater 
number, and greater variety of both types of support. Disadvantaged women, on the contrary, were less likely to draw on any support at all. Evidence for the substitution of informal for formal support is suggested by research showing that disadvantaged women are more likely to turn to formal sources of support. Women from minority backgrounds (Hollenshead, Dai, Ragsdale, Massey, \& Scott, 2006; Kaukinen, 2004), with less income (Barrett \& St. Pierre, 2011; Meyer, 2010), with less education (Belknap et al., 2009), and who have been in abusive relationships longer (Anderson et al., 2014) have been shown to rely less on informal support. Among Canadian women who recently exited abusive relationships, formal service utilizers are more likely to be economically disadvantaged, caring for dependent children, currently coping with health problems (Ford- Gilboe et al., 2015). Together, this suggests that disadvantaged women have less access to effective social support.

Participation in material and traditional exchanges is likely to provide access to informal support; participation in the alcohol co-use network may heighten risk for DV and social isolation. For this reason, we analyze the three domains separately to understand how a woman's social relationships with others within the community influence their access to different types of potential IPV support.

Research Question 1: Do the data support an isolation hypothesis, a substitution hypothesis, both, or neither?

Research Question 2: Do peer, traditional, and material sources of social support relate to DV help nominations in similar or different ways?

The answers to these two research questions add to our understanding of how access to two types of DV support is embedded in the larger set of social relations of an indigenous community. We use network data collected from multiple foci of social life to learn whether formal and informal support are interchangeable, or whether formal sources are a second-tier substitute for interpersonal connections that provide access to informal support. 


\section{Method}

The study analyzed data collected from a network survey of the adult residents of a predominately Inuit (92\% Indigenous) community in Arctic Canada. The network survey was supplemented by ethnographic and qualitative interviewing on life in the community, local history, and traditional cultural activities by two cultural anthropologists. Prior analyses of these data have documented important community dynamic related to food provisioning and economic security/insecurity (Dombrowski et al., 2013). The project was supported by a grant from the U.S. National Science Foundation, Office of Polar Programs, Division of Arctic Social Sciences, with the approval of the Nunatsiavut Research Committee. All of the material contained here was obtained with the informed consent of all participants. The research questions were developed in collaboration with the community through a process of focus group meetings in 2009. The final research instrument and methods were reviewed and approved by the Nunatsiavut Research Committee. Primary data collection was done by two ethnographers with the help of four members of the community. Project results were presented to the community in 2012 in a series of public presentations. Copies of all data related to the project (in anonymous form) were given to the Nunatsiavut Research Committee for their use. All publications related to the project data are reviewed by the Nunatsiavut Research Committee prior to publication.

Participants and sampling. The demographic composition of the community is typical of Native American communities. The population is young-we estimated that $42 \%$ of the people are younger than 30 while $18 \%$ are older than age $50-$ and housing is difficult to come by. Most members of the community have not finished high school and are not employed full-time; the average personal weekly income was CAD \$233, and the average household income was around CAD\$550. The history of the community continues to structure social relationships, and access to informal support. About 10\% of community members were relocated from outlying communities by the Canadian government and they remain socially separate from those born within the community (Dombrowski et al., 2013; Dombrowski, Habecker, Gauthier, Khan \& Moses, 2016; Brice-Bennett, 1977). 
Participants were recruited through peer-referral method of Respondent Driven Sampling (Heckathorn, 2002). Following informed consent procedures, each participant was compensated with CAD\$30 to complete a roughly 1.5-hr interview and offered an additional CAD $\$ 10$ for each of up to three recruits they brought into the study (Dombrowski et al., 2013). In total, 334 adult residents (18 years old or older) completed the interview over a period of 5.5 months. However, we limit our analyses to interview responses given by women in the community. Roughly, half the sample of final sample was women (171), and of these, 158 provided DV assistance nominations that were unambiguously directed to either individuals or institutions.

Measures. This article uses measures collected from the network survey portion of the data collection. We use self-reports to ascertain type of nomination, social support received, and demographic characteristics.

Dependent variable. The dependent variable in our analysis is the type of DV support each woman chose when asked who she would turn to/ or had turned to for help with IPV, either for herself or a close associate. We separated the nominations into three groups: women who endorsed an individual for informal support, women who endorsed formal support, and women who made no endorsement. Only 13 women reported both an informal and formal source of support and we have excluded them from the analysis. We combined these women with the women who nominated an individual because we are primarily interested in who has access to informal support. Results from supplementary analyses where we combined these women with the women who nominated an individual were not substantially different from the results we present here.

Independent variables. A series of dichotomous scores measuring exchanges of material and nonmaterial support sent to each woman across several domains over the last 12 months measure women's potential access to informal support. Exchanges within the material support domain include housing assistance, job assistance, store food assistance. Exchanges within the traditional support domain include provision of country food and traditional knowledge support. 
In addition, potential kin support is measured through the presence of parents and siblings. ${ }^{2}$ Alcohol co-use is separated out as its own domain because it not only indicates a potential for emotional support, but it also potentially denotes relationships that may contribute to, rather than mitigate, an abusive situation. The presence of alcohol-inclusive relationships is measured as any report of alcohol couse partners.

Sociodemographic characteristics. Age, weekly household income, high school completion (reference category), employment status (currently unemployed), natal status (born outside the community), marital status (cohabiting, divorced, married or single/widowed), and number of children are included as controls. Supplementary models were performed using variables measuring the informal support respondents gave to others in the community across the same domains. These controls are not included here because they were found not to significantly improve model fit.

Data analysis. We use multinomial logistic regression to analyze the relationship between social integration and the type of support women endorsed. Interpretation of these models closely matches interpretation of ordinary logistic regression. The main difference is that the former predict membership in multiple groups of interest. As with ordinary logistic regression, coefficients are reported as log odds, here comparing predictors for membership in the groups of interest against membership in the reference group. We first test the isolation hypothesis. Women who make no recommendation are the reference category against which we compare women who make either formal or informal recommendations. We expect that the women who make either type of recommendation will be more integrated into the community than women who make no recommendation (the reference category). Second, we test the substitution hypothesis. Women who make an informal recommendation are the reference category against which we compare women who make either a formal recommendation or who make no recommendation. We expect to find that women who made formal recommendations or who made no recommendation will be less integrated into the community compared with those who made an informal one (the reference category). Within the test 
of each hypothesis, we include three blocks of social support: (a) peer support (alcohol co-use), (b) traditional/cultural support (kinship, traditional knowledge, and country foods), and (c) material assistance (housing, job assistance, store-bought foods).

\section{Results}

Our goal is to understand how the wider social context is associated with women's ability to make DV nominations. We present the correlations between the number of nominations for DV support women made and the number of nominations they made across the other network domains in Table 1 to understand how the social domains are correlated with each other, as well as how strongly they are correlated with the number of DV assistance nominations women made. These correlations provide general information about women's access to DV support rather than access to specific types (formal and informal). The first row of Table 1 shows that women who make more DV support nominations also make more nominations across the board in all exchanges except kinship. They nominate more alcohol co-use partners, people they can go to for housing assistance, job search assistance, store-bought food, traditional knowledge, country foods. The correlation is even stronger with housing assistance $(r=.381)$, traditional

Table 1. Correlations Between the Number of Nominations for Domestic Violence Assistance Women Make Across All Three Types of Nominations and the Nominations They Make Across Eight Other Network Domains $(N=158)$.

\begin{tabular}{|c|c|c|c|c|c|c|c|c|}
\hline & 2 & 3 & 4 & 5 & 6 & 7 & 8 & 9 \\
\hline 1. Domestic violence assistance nominations made & $.191+$ & $.324^{\star \star \star}$ & $.334^{* * *}$ & .033 & .078 & $.381^{* * *}$ & $.284^{\star \star *}$ & $.224^{*}$ \\
\hline 2. Alcohol co-use nominations made & - & .044 & .096 & $.153^{+}$ & $.140^{+}$ & .118 & .022 & -.008 \\
\hline 3. Traditional knowledge source nominations made & & - & $.473^{* * *}$ & -.004 & .117 & $.402^{* * *}$ & $.212^{\star \star}$ & $.363^{* * *}$ \\
\hline 4. Country food source nominations made & & & - & -.040 & .076 & $.392^{\star \star \star}$ & $.250^{\star *}$ & $.319 * \star \star$ \\
\hline 5. Parental nominations made & & & & - & .083 & $.161^{\star}$ & .097 & $.186^{\star}$ \\
\hline 6. Sibling nominations made & & & & & - & .056 & .013 & -.001 \\
\hline 7. Housing assistance nominations made & & & & & & - & $.338^{\star * *}$ & $.312^{\star \star \star}$ \\
\hline 8. Jobs assistance nominations made & & & & & & & - & $.152^{*}$ \\
\hline 9. Store food source nominations made & & & & & & & & - \\
\hline
\end{tabular}

Note. Network Domain 1 indicates perceived relationships in a peer network (friendliness); Network Domains 3, 4, 5, and 6 indicate receiving assistance in a traditional domain; Network Domains 7, 8, and 9 indicate receiving material assistance.

$+p \leq .10 ;{ }^{*} p \leq .05 ;{ }^{* \star} p \leq .01 ;{ }^{* \star *} p \leq .001$ 
knowledge $(r=.324)$, and country food sources $(r=.334)$. However, women who make more DV support nominations are no more likely to have parents or siblings living in the community and so we exclude these two measures of potential support from subsequent analyses. ${ }^{1}$ These results point to the importance of women's access to non-kin based culturally specific exchanges and to material assistance. Women who have someone with whom they can participate in traditional cultural practices also report more DV assistance recommendations. Likewise, women who report receiving material assistance report more DV assistance recommendations.

Descriptive statistics for the sample are in Table 2. Overall, women in our sample most frequently made informal endorsements. Almost half $(44 \%)$ of the sample endorsed at least one individual, while $23 \%$ endorsed at least one formal source of support and a third (33\%) made no endorsement. The demographic profile of the sample is similar to

Table 2. Sample Characteristics.

\begin{tabular}{lrr} 
& M or \% & $S D$ \\
\hline Nomination type & & \\
$\quad$ Individuals & $44 \%$ & $4 \%$ \\
$\quad$ Institutions & $23 \%$ & $3 \%$ \\
$\quad$ Neither & $33 \%$ & $4 \%$ \\
Demographic characteristics & & \\
$\quad$ Age & 36.96 & 14.56 \\
$\quad$ Weekly household income & 548.88 & 302.17 \\
Employed & $48 \%$ & $4 \%$ \\
$\quad$ Completed high school & $37 \%$ & $4 \%$ \\
$\quad$ Born outside the community & $11 \%$ & $2 \%$ \\
Marital status & & \\
$\quad$ Single/widowed & $39 \%$ & $4 \%$ \\
$\quad$ Cohabiting & $32 \%$ & $3 \%$ \\
$\quad$ Married & $22 \%$ & $2 \%$ \\
$\quad$ Divorced & $7 \%$ & 1.45 \\
Peer relationships & & \\
$\quad$ Drinking partners & 1.21 & 0.86 \\
Traditional help sources & & 0.82 \\
$\quad$ Traditional knowledge & 1.37 & \\
$\quad$ Country food & 1.64 & 0.84 \\
Material help sources & & 0.89 \\
$\quad$ Housing assistance & 1.23 & 0.89 \\
$\quad$ Jobs assistance & 0.96 & \\
$\quad$ Store food sources & 0.99 & \\
Total $N$ = 158 & & \\
\hline
\end{tabular}


the demographic profile of the community as a whole. The sample is generally young and economically disadvantaged. The women are 37 years old on average, 37\% have completed high school, half are unemployed and their average weekly household income is CAD\$548.88. Approximately, 10\% were born outside of the community. About half are currently in a romantic relationship; $22 \%$ are currently married; and $32 \%$ are currently cohabiting. We combined the two widowed women with single women because neither groups have a current romantic partner. We assign cohabiting women to the reference group in our analysis because previous research indicates that they are at higher risk for experiencing DV. Women nominated just over one drinking partner on average, three sources of traditional help, and three sources of material assistance.

We begin testing our hypotheses below. We analyze the relationship between the number of drinking partners a woman reports and the log odds that they endorse a formal DV support source, or an informal one in Table 3. Both types of responses are compared to the reference category-women who make no recommendation. The first column presents the log odds a woman recommends an informal source of support, given her integration into the alcohol co-use network. The only coefficient that reaches statistical significance in the first column indicates that women who name more drinking partners are more likely to recommend an informal source of DV assistance. For every drinking partner she names, the odds of a woman recommending an informal source increases 1.5 times. The next column presents the log odds that a woman recommends a formal source of support. The number of people a woman nominates as a drinking partner is not significantly associated with an increase or decrease in the log odds that a woman will recommend a formal source of support.

Next, we present the relationship between integration into the traditional network and type of DV support recommendation in the third and fourth columns of Table 3 . Women who receive traditional help are more likely to name an informal support than they are to make no recommendation. Specifically, the odds of a woman who reports receiving country food making an informal nomination increases 3 times for each source she names compared with a woman who names none. Women who receive traditional knowledge support are also more likely to make an informal nomination but the relationship is 
Table 3. Log Odds of a Woman Providing an Informal Recommendation or a Formal Recommendation Compared With Providing No Recommendation $(N=158)$.

\begin{tabular}{|c|c|c|c|c|c|c|}
\hline & \multicolumn{2}{|c|}{ Companionship } & \multicolumn{2}{|c|}{ Traditional Assistance } & \multicolumn{2}{|c|}{ Material Assistance } \\
\hline & $\begin{array}{c}\text { Informal } \\
\text { Support }\end{array}$ & $\begin{array}{l}\text { Formal } \\
\text { Support }\end{array}$ & $\begin{array}{l}\text { Informal } \\
\text { Support }\end{array}$ & $\begin{array}{l}\text { Formal } \\
\text { Support }\end{array}$ & $\begin{array}{l}\text { Informal } \\
\text { Support }\end{array}$ & $\begin{array}{l}\text { Formal } \\
\text { Support }\end{array}$ \\
\hline Intercept & $\begin{array}{c}0.362 \\
(1.140)\end{array}$ & $\begin{array}{c}0.711 \\
(1.140)\end{array}$ & $\begin{array}{c}-0.555 \\
(1.270)\end{array}$ & $\begin{array}{c}0.654 \\
(1.270)\end{array}$ & $\begin{array}{c}-1.853 \\
(1.389)\end{array}$ & $\begin{array}{c}0.381 \\
(1.389)\end{array}$ \\
\hline \multicolumn{7}{|l|}{ Demographic characteristics } \\
\hline Age & $\begin{array}{c}-0.006 \\
(0.020)\end{array}$ & $\begin{array}{r}-0.041 \\
(0.02)\end{array}$ & $\begin{array}{c}-0.033 \\
(0.021)\end{array}$ & $\begin{array}{c}-0.057^{*} \\
(0.021)\end{array}$ & $\begin{array}{c}0.012 \\
(0.022)\end{array}$ & $\begin{array}{r}-0.038 \\
(0.022)\end{array}$ \\
\hline Weekly household income & $\begin{array}{c}0.000 \\
(0.001)\end{array}$ & $\begin{array}{c}0.000 \\
(0.001)\end{array}$ & $\begin{array}{c}-0.001 \\
(0.001)\end{array}$ & $\begin{array}{c}-0.001 \\
(0.001)\end{array}$ & $\begin{array}{c}0.000 \\
(0.001)\end{array}$ & $\begin{array}{r}-0.001 \\
(0.001)\end{array}$ \\
\hline Completed high school & $\begin{array}{c}0.471^{+} \\
(0.477)\end{array}$ & $\begin{array}{c}0.930 \\
(0.477)\end{array}$ & $\begin{array}{c}0.325 \\
(0.496)\end{array}$ & $\begin{array}{c}0.760 \\
(0.496)\end{array}$ & $\begin{array}{c}-0.137 \\
(0.519)\end{array}$ & $\begin{array}{c}0.625 \\
(0.519)\end{array}$ \\
\hline Unemployed & $\begin{array}{c}-0.263 \\
(0.480)\end{array}$ & $\begin{array}{c}0.108 \\
(0.480)\end{array}$ & $\begin{array}{c}-0.296 \\
(0.502)\end{array}$ & $\begin{array}{c}-0.006 \\
(0.502)\end{array}$ & $\begin{array}{c}-0.380 \\
(0.521)\end{array}$ & $\begin{array}{c}0.063 \\
(0.521)\end{array}$ \\
\hline Born outside the community & $\begin{array}{c}-1.218 \\
(0.945)\end{array}$ & $\begin{array}{c}1.180 \\
(0.945)\end{array}$ & $\begin{array}{c}-0.939 \\
(1.026)\end{array}$ & $\begin{array}{c}1.478 \\
(1.026)\end{array}$ & $\begin{array}{c}-1.472 \\
(1.003)\end{array}$ & $\begin{array}{r}1.110 \\
(1.003)\end{array}$ \\
\hline Divorced (base $=$ cohabiting) & $\begin{array}{c}-0.784 \\
(0.949)\end{array}$ & $\begin{array}{c}0.713 \\
(0.949)\end{array}$ & $\begin{array}{c}-0.034 \\
(1.036)\end{array}$ & $\begin{array}{c}1.240 \\
(1.036)\end{array}$ & $\begin{array}{c}-0.157 \\
(1.016)\end{array}$ & $\begin{array}{c}0.843 \\
(1.016)\end{array}$ \\
\hline Currently married & $\begin{array}{c}-0.812 \\
(0.650)\end{array}$ & $\begin{array}{c}-0.072 \\
(0.650)\end{array}$ & $\begin{array}{c}-0.431 \\
(0.677)\end{array}$ & $\begin{array}{c}0.064 \\
(0.677)\end{array}$ & $\begin{array}{c}-0.381 \\
(0.705)\end{array}$ & $\begin{array}{c}0.109 \\
(0.705)\end{array}$ \\
\hline Single/widowed & $\begin{array}{c}-0.226 \\
(0.487)\end{array}$ & $\begin{array}{c}-0.288 \\
(0.487)\end{array}$ & $\begin{array}{c}-0.244 \\
(0.525)\end{array}$ & $\begin{array}{c}-0.377 \\
(0.525)\end{array}$ & $\begin{array}{c}0.007 \\
(0.533)\end{array}$ & $\begin{array}{r}-0.341 \\
(0.533)\end{array}$ \\
\hline Number of children & $\begin{array}{c}0.117 \\
(0.149)\end{array}$ & $\begin{array}{c}-0.027 \\
(0.149)\end{array}$ & $\begin{array}{c}0.204 \\
(0.175)\end{array}$ & $\begin{array}{c}0.032 \\
(0.175)\end{array}$ & $\begin{array}{c}0.250 \\
(0.177)\end{array}$ & $\begin{array}{r}0.030 \\
(0.177)\end{array}$ \\
\hline \multicolumn{7}{|l|}{ Peer relationships } \\
\hline Drinking partners & $\begin{array}{c}0.421^{*} \\
(0.170)\end{array}$ & $\begin{array}{c}0.280 \\
(0.170)\end{array}$ & & & & \\
\hline \multicolumn{7}{|l|}{ Traditional help sources } \\
\hline Country food & & & $\begin{array}{l}1.111^{* \star *} \\
(0.356)\end{array}$ & $\begin{array}{c}0.335 \\
(0.356)\end{array}$ & & \\
\hline Traditional knowledge & & & $\begin{array}{r}0.557^{\dagger} \\
(0.331)\end{array}$ & $\begin{array}{c}0.552 \\
(0.331)\end{array}$ & & \\
\hline \multicolumn{7}{|l|}{ Material help sources } \\
\hline Housing assistance & & & & & $\begin{array}{c}0.714^{*} \\
(0.297)\end{array}$ & $\begin{array}{r}.140 \\
(0.297)\end{array}$ \\
\hline Job assistance & & & & & $\begin{array}{c}0.678^{*} \\
(0.285)\end{array}$ & $\begin{array}{c}0.568 \\
(0.285)\end{array}$ \\
\hline Store food assistance & & & & & $\begin{array}{c}0.573^{*} \\
(0.265)\end{array}$ & $\begin{array}{c}0.137 \\
(0.265)\end{array}$ \\
\hline
\end{tabular}

Note. Standard errors in parentheses.

$+p \leq .10 .{ }^{*} p \leq .05 .{ }^{* *} p \leq .01 .{ }^{* \star *} p \leq .001$. 
only marginally significant. In both cases, women with more traditional sources of support are no more likely to make a formal recommendation than to make none.

The final model, measuring the relationship between receiving material assistance and nominating either an informal or a formal source of support is presented in the final two columns of Table 3. Women who have named more sources of material help in all three categories-housing assistance, job assistance, and store food assistanceare more likely to make an informal recommendation than they are to make none. The odds of making an informal recommendation are doubled with each housing and store food assistance source a woman names, and 1.77 times higher with each source of job assistance. Women who receive housing support are more likely to make a formal recommendation, but neither job assistance nor store for assistance is significantly associated with making a formal recommendation.

In the next set of models shown in Table 4, we repeat the previous analysis, but change the baseline comparison to women who endorse an informal source of support to directly test the substitution hypothesis. The results in the first column indicate that the odds that women endorse formal support, relative to informal support are 11 times higher when they are born elsewhere and relocated into the community. The odds of making a formal recommendation are 4.5 times higher among divorced (though the difference is only marginally significant) and divorced is the only marital status to have a sizable effect relative to cohabiting women. No other relationships were detected; the number of alcohol partners women nominate has no discernable relationship with endorsing a formal source of DV support compared with an informal one. The only significant effect indicates that the odds of women who are named by others as a drinking partner are just over half as likely to make no endorsement as they are to make an informal one. Substantively this indicates that women who name many drinking partners are likely receiving enough social support from them that they are equally likely to have either an informal or a formal source for DV support.

The relationship between integration into the traditional exchange network and type of endorsement is examined in the third and fourth columns of Table 4. The odds of making a formal nomination compared with an informal one are less than half for each source of 
Table 4. Log Odds of a Woman Providing No Recommendation, or a Formal Recommendation Compared With an Informal Recommendation $(N=158)$.

\begin{tabular}{|c|c|c|c|c|c|c|}
\hline & \multicolumn{2}{|c|}{ Companionship } & \multicolumn{2}{|c|}{ Traditional Assistance } & \multicolumn{2}{|c|}{ Material Assistance } \\
\hline & $\begin{array}{c}\text { No } \\
\text { Support }\end{array}$ & $\begin{array}{l}\text { Formal } \\
\text { Support }\end{array}$ & $\begin{array}{c}\text { No } \\
\text { Support }\end{array}$ & $\begin{array}{l}\text { Formal } \\
\text { Support }\end{array}$ & $\begin{array}{c}\text { No } \\
\text { Support }\end{array}$ & $\begin{array}{l}\text { Formal } \\
\text { Support }\end{array}$ \\
\hline Intercept & $\begin{array}{l}-0.362 \\
(1.140)\end{array}$ & $\begin{array}{c}0.349 \\
(1.140)\end{array}$ & $\begin{array}{c}0.555 \\
(1.270)\end{array}$ & $\begin{array}{c}1.208 \\
(1.270)\end{array}$ & $\begin{array}{c}1.853 \\
(1.389)\end{array}$ & $\begin{array}{l}2.228 \\
(1.53)\end{array}$ \\
\hline \multicolumn{7}{|l|}{ Demographic characteristics } \\
\hline Age & $\begin{array}{c}0.006 \\
(0.020)\end{array}$ & $\begin{array}{c}-0.035 \\
(0.020)\end{array}$ & $\begin{array}{c}0.033 \\
(0.021)\end{array}$ & $\begin{array}{c}-0.023 \\
(0.021)\end{array}$ & $\begin{array}{c}-0.012 \\
(0.022)\end{array}$ & $\begin{array}{c}-0.050 \\
(0.026)\end{array}$ \\
\hline Weekly household income & $\begin{array}{c}0.000 \\
(0.001)\end{array}$ & $\begin{array}{c}0.000 \\
(0.001)\end{array}$ & $\begin{array}{c}0.001 \\
(0.001)\end{array}$ & $\begin{array}{c}0.000 \\
(0.001)\end{array}$ & $\begin{array}{c}0.000 \\
(0.001)\end{array}$ & $\begin{array}{c}0.000 \\
(0.001)\end{array}$ \\
\hline Completed high school & $\begin{array}{l}-0.471 \\
(0.477)\end{array}$ & $\begin{array}{c}0.459 \\
(0.477)\end{array}$ & $\begin{array}{c}-0.325 \\
(0.496)\end{array}$ & $\begin{array}{c}0.436 \\
(0.496)\end{array}$ & $\begin{array}{c}0.137 \\
(0.519)\end{array}$ & $\begin{array}{c}0.761 \\
(0.51)\end{array}$ \\
\hline Unemployed & $\begin{array}{c}0.263 \\
(0.480)\end{array}$ & $\begin{array}{c}0.370 \\
(0.480)\end{array}$ & $\begin{array}{c}0.296 \\
(0.502)\end{array}$ & $\begin{array}{c}0.290 \\
(0.502)\end{array}$ & $\begin{array}{c}0.380 \\
(0.521)\end{array}$ & $\begin{array}{c}0.444 \\
(0.539)\end{array}$ \\
\hline Born outside the community & $\begin{array}{c}1.218 \\
(0.945)\end{array}$ & $\begin{array}{l}2.398^{\star} \\
(0.945)\end{array}$ & $\begin{array}{c}0.940 \\
(1.026)\end{array}$ & $\begin{array}{l}2.417^{*} \\
(1.026)\end{array}$ & $\begin{array}{c}1.472 \\
(1.003)\end{array}$ & $\begin{array}{l}2.581^{*} \\
(1.130)\end{array}$ \\
\hline Divorced (base = cohabiting) & $\begin{array}{c}0.784 \\
(0.949)\end{array}$ & $\begin{array}{r}1.497+ \\
(0.949)\end{array}$ & $\begin{array}{c}0.034 \\
(1.036)\end{array}$ & $\begin{array}{c}1.274 \\
(1.036)\end{array}$ & $\begin{array}{c}0.157 \\
(1.016)\end{array}$ & $\begin{array}{c}0.999 \\
(0.955)\end{array}$ \\
\hline Currently married & $\begin{array}{c}0.812 \\
(0.650)\end{array}$ & $\begin{array}{c}0.740 \\
(0.650)\end{array}$ & $\begin{array}{c}0.430 \\
(0.677)\end{array}$ & $\begin{array}{c}0.494 \\
(0.677)\end{array}$ & $\begin{array}{c}0.381 \\
(0.705)\end{array}$ & $\begin{array}{c}0.488 \\
(0.774)\end{array}$ \\
\hline Single/widowed & $\begin{array}{c}0.226 \\
(0.487)\end{array}$ & $\begin{array}{c}-0.062 \\
(0.487)\end{array}$ & $\begin{array}{c}0.244 \\
(0.525)\end{array}$ & $\begin{array}{c}-0.133 \\
(0.525)\end{array}$ & $\begin{array}{c}-0.007 \\
(0.533)\end{array}$ & $\begin{array}{c}-0.348 \\
(0.541)\end{array}$ \\
\hline Number of children & $\begin{array}{l}-0.117 \\
(0.149)\end{array}$ & $\begin{array}{c}-0.144 \\
(0.149)\end{array}$ & $\begin{array}{c}-0.204 \\
(0.175)\end{array}$ & $\begin{array}{c}-0.172 \\
(0.175)\end{array}$ & $\begin{array}{c}-0.250 \\
(0.177)\end{array}$ & $\begin{array}{c}-0.220 \\
(0.179)\end{array}$ \\
\hline \multicolumn{7}{|l|}{ Peer relationships } \\
\hline Drinking Partners & $\begin{array}{c}-0.421^{*} \\
(0.170)\end{array}$ & $\begin{array}{c}-0.140 \\
(0.170)\end{array}$ & & & & \\
\hline \multicolumn{7}{|l|}{ Traditional help sources } \\
\hline Country food & & & $\begin{array}{c}-1.111^{* * *} \\
(0.356)\end{array}$ & $\begin{array}{c}-0.776^{\star} \\
(0.356)\end{array}$ & & \\
\hline Traditional knowledge & & & $\begin{array}{c}-0.557^{\dagger} \\
(0.331)\end{array}$ & $\begin{array}{c}-0.006 \\
(0.331)\end{array}$ & & \\
\hline \multicolumn{7}{|l|}{ Material help sources } \\
\hline Housing assistance & & & & & $\begin{array}{r}-0.714^{*} \\
(0.297)\end{array}$ & $\begin{array}{r}-0.573+ \\
(0.321)\end{array}$ \\
\hline Job assistance & & & & & $\begin{array}{r}-0.678^{*} \\
(0.285)\end{array}$ & $\begin{array}{c}-0.110 \\
(0.273)\end{array}$ \\
\hline Store food assistance & & & & & $\begin{array}{c}-0.573^{*} \\
(0.265)\end{array}$ & $\begin{array}{c}-0.435 \\
(0.267)\end{array}$ \\
\hline
\end{tabular}

Note. Standard errors in parentheses.

$+p \leq .10 ;{ }^{*} p \leq .05 ;{ }^{* *} p \leq .01 ;{ }^{* * *} p \leq .001$ 
country food assistance a woman names. The odds of a woman making a formal nomination decrease by almost half for every traditional knowledge source she names. In general, the relationship between integration and type of DV assistance endorsement the women in the sample made is qualitatively similar across the alcohol partnership and traditional assistance.

The final model, measuring the relationship between receiving material assistance and nominating an informal source of support, or making no recommendation is presented in the final two columns of Table 4. We find once again that women born elsewhere are most likely to rely on formal sources of support, relative to informal sources. We also find that the odds of making a formal recommendation decrease by half for each source of housing assistance a woman has, compared with an informal one.

The relative magnitudes of each network factor that reached statistical significance are depicted in the figures below. Figure 1 below shows the predicted probability of each type of DV support nomination given increasing numbers of nominations as a drinking partner for a typical woman from our sample (she is a 37-year-old employed woman who has no high school degree and who is in a cohabiting relationship). The predicted probability for a typical woman to make an informal nomination if she makes no drinking partner nominations is 0.49 in the peer support model; it increases to 0.90 when women makes eight drinking partner observations (the highest number observed in the data).

Figure 2 below depicts the relationships between receiving traditional support (country food and traditional knowledge) and type of support endorsed for the typical woman described above. The first panel depicts how the predicted probability of a woman nominating each type of DV support source (informal, formal, or none) changes as the number of country food sources she has available increases. The findings offer strong support for the isolation hypothesis within the country food domain. The addition of more country food sources has a strong, positive effect across the entire range of empirically observed nominations. The predicted probability that a woman will make an informal nomination increases from 0.12 to 0.96 as the number of country food sources she lists increases from o to 5 (the empirical maximum). The predicted probability that a woman will 


\section{Alcohol co-use partners}

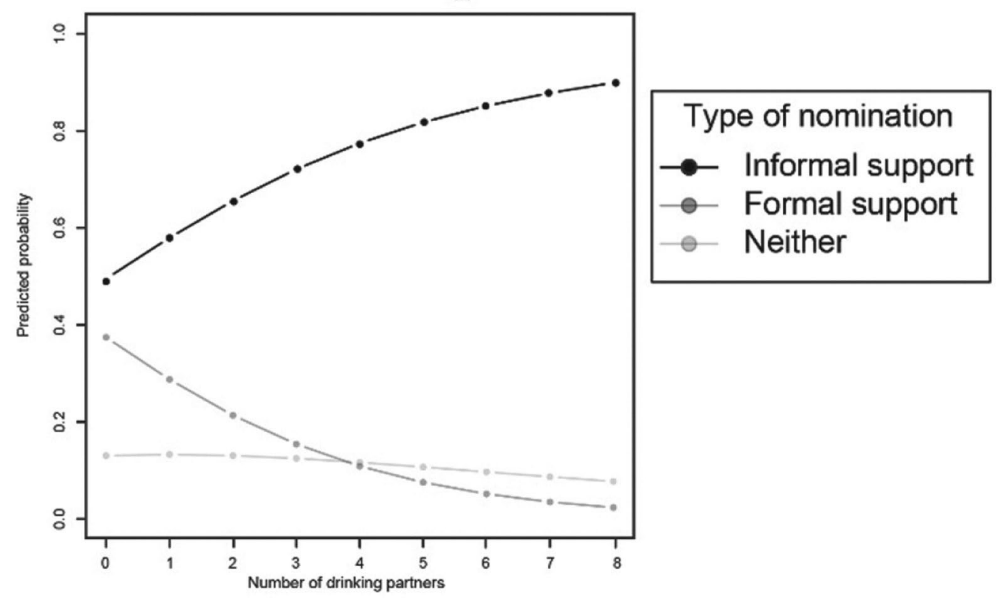

Figure 1. Predicted probability of each type of domestic violence support nomination by number of alcohol co-use partners named $(\mathrm{N}=158)$. Note. Predicted probabilities are calculated from the companionship model shown in Table 3 with all continuous variables set to their mean and categorical variables set to the most common value.

Country food sources

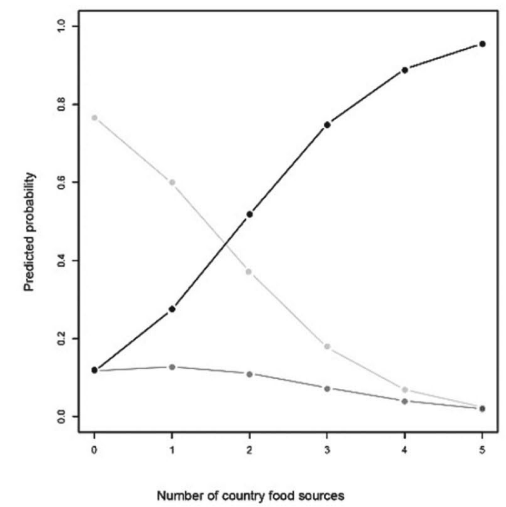

Traditional knowledge sources

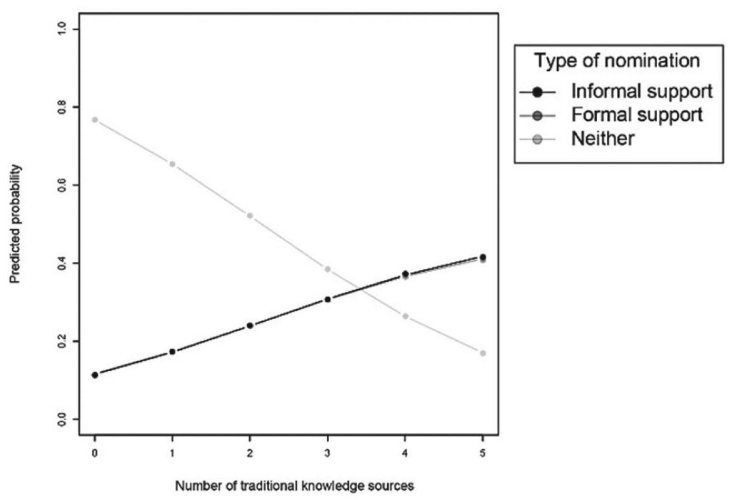

Figure 2. Predicted probability of each type of domestic violence support nomination by the number of traditional sources of support named $(\mathrm{N}=158)$. Note. Predicted probabilities are calculated from the traditional assistance model shown in Table 3 with all continuous variables set to their mean and categorical variables set to the most common value. 
make no domestic support nomination declines in a mirror image of informal nominations. They drop off from 0.77 to 0.02 as the number of country food sources increases from o to 5. Finally, we find some support for the substitution hypothesis as women are slightly less likely to make a formal recommendation as their reported country food sources increase.

Moving on to the second panel of Figure 2, the effect of traditional knowledge sources provides more evidence for the isolation hypothesis. The effect is similar, but weaker than the effect of country food sources for the predicted probability that a woman will nominate an informal source of support. The relationship, however, between utilization of traditional knowledge sources and the probability that a woman will make a formal DV support nomination is quite different for a woman's access to formal support. Here, we find that women with no other sources of support are equally likely to make either a formal or an informal nomination.

Finally, Figure 3 shows the relationship between material support and type of DV support nomination for an average woman who has no other source of support. The first panel shows how an increase in the number of housing assistance changes the predicted probabilities of a woman making each type of DV recommendation. Here, we see more evidence in support of the isolation hypothesis. The probability that she will make an informal recommendation increases quickly with an increasing number of housing supporters relative to both other options, whereas her predicted probability of making no nomination decreases. There is also more weak support for the isolation hypothesis. The probability that she will make a formal nomination decreases from 0.16 to 0.07 when she has five sources of housing support compared with none.

The effect of job assistance is depicted in the second panel of Figure 3. Women who report more sources of job support are more likely to make both informal and formal recommendations, and less likely to make no recommendation at all. However, the relationship between job support and making a formal recommendation is only weak. We find a similar picture in the third panel depicting the relationship between store-bought food assistance and the type of recommendation a woman would make if she had no other sources of support. Here again, we see that women with more sources of store-bought food 

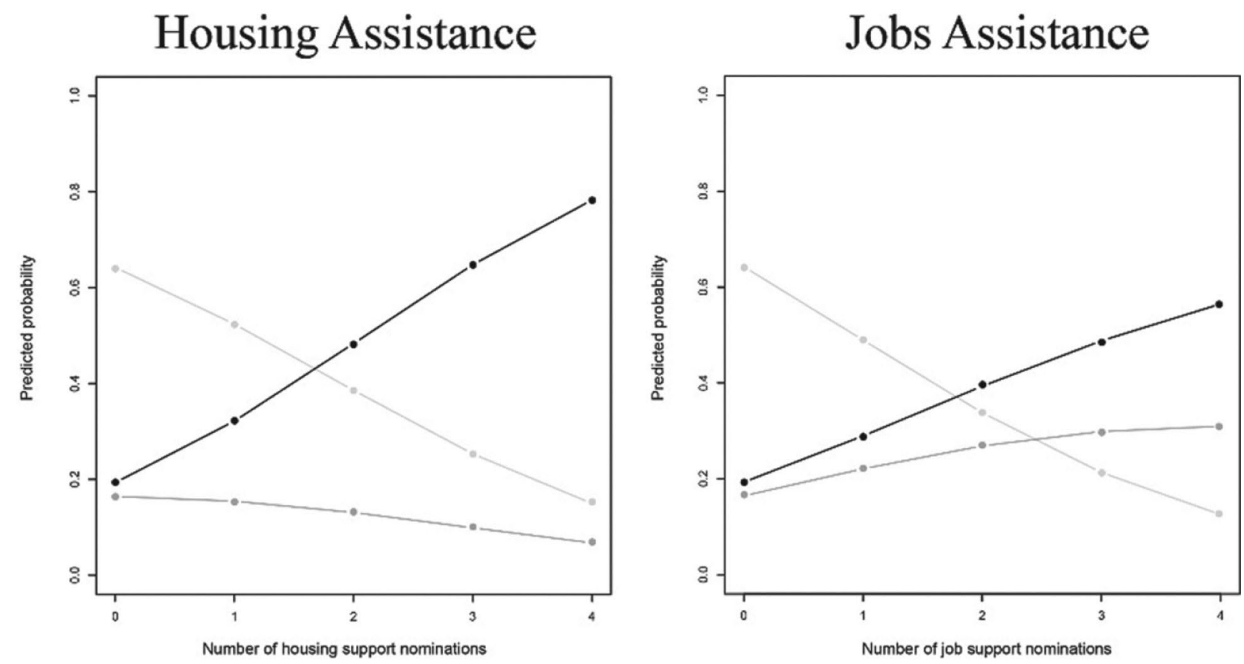

Store-bought food assistance
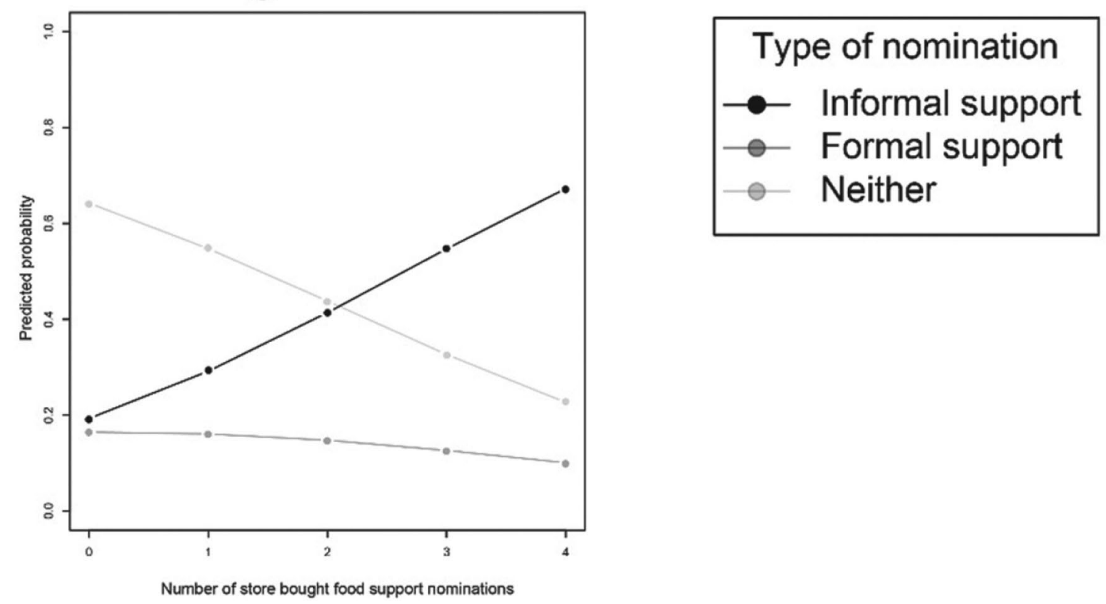

Figure 3. Predicted probability of each type of domestic violence support nomination by the number of material sources of support named $(\mathrm{N}=158)$. Note. Predicted probabilities are calculated from the traditional assistance model shown in Table 3 with all continuous variables set to their mean and categorical variables set to the most common value.

assistance are more likely to make an informal recommendation relative to a formal one, or to make no recommendation at all. Together, all three panels provide evidence that is consistent with the isolation hypothesis.

Overall, we find support for the isolation hypothesis; women who are more disadvantaged and less socially integrated within the community were less likely to recommend either formal or informal 
support. We suggest that their general lack of integration leads to less access to DV support, informal support in particular. We find limited, domain-specific support for the substitution hypothesis. When more disadvantaged women who are less integrated into the housing assistance network were more inclined toward formal support compared with informal support.

\section{Discussion}

This article adds to our understanding of different channels of support for indigenous women experiencing DV. We expected to find that more advantaged women (younger, more educated, employed, born in the community, currently married) would have more access to informal and formal support. In general, our findings were consistent with these expectations. We found support for both isolation and substitution hypotheses across the three domains of social support we studied (alcohol co-use, traditional support, and material assistance).

Women who name more alcohol co-use partners are more likely to make a DV nomination. This finding suggests that social connections that are made and maintained through alcohol co-use is associated with greater support, even while previous research has found alcohol use contributing to the risk of experiencing DV. This suggests that there are potential social consequences for women who practice abstinence within this community context. Qualitative interviews revealed that the prevalence of alcohol-related problems is a serious concern to the community. The best approach is likely, therefore, a widespread reduction of alcohol consumption within the wider community so that alcohol use is no longer an important context in which to carry out social discourse.

We also find that women who have more housing support and "traditional" sources of support (traditional knowledge and country food exchanges) are also more able to make DV assistance nominations; however, more kinship ties (being a parent or having siblings) are not strongly related to making DV nominations. This suggests that involvement in traditional spheres is partially protective of support. This finding may help contextualize our understanding of why relocatees into the community are consistently less likely to be able to make any 
nomination. Those particular women have experienced the greatest disruption to traditional means of support. This also points to the potential importance of elders or other people who carry on traditional knowledge and hunting practices in the community, distinct from kin, to play a supportive role to women experiencing DV.

Women who had been on the receiving end of material assistance were more likely to make an informal endorsement than a formal one. This points to the importance of social relationships within the context of a small, rural, geographically isolated community. The conditions of rural life magnify many of the challenges women face in leaving abusive situations, including alternate housing arrangements and access to food. Women who do not have material support were less likely to make either type of nomination, which may indicate that secure access to material necessities help empower women to seek (minimally) formal support. From this, we can conclude that programs for material support of women remain critical to stemming long-term IPV.

Although our data have provided rich insight about social integration into several important facets of community life, there are three main limitations. First, we cannot differentiate women who have experienced DV, or who are currently experiencing DV from those who are/have not. Instead, we focus on women's potential sources of support. As such, we do not examine whether experience with IPV actually leads to or coincides with social isolation in the community. Future studies may wish to examine the relationship between DV and social withdrawal from other arenas of social life in this community. Second, we draw our data from an idiosyncratic sample. We study a single indigenous community in Canada's North. Although the community is typical of its kind, the extent to which our finding can be generalized to other, less geographically isolated Native American or North American indigenous communities is unclear. The experience of relocation has an important role in structuring social life within this community (Dombrowski et al., 2013) and our results suggest that individuals whose families have experience with relocation are more likely to turn to formal sources of support net of their social participation. However, we note that the number of women with relocation experience is very small $(N=17)$ and, therefore, statistical analysis should be treated as suggestive only. 
DV is a persistent problem in rural, indigenous communities, and understanding access to support is consequently imperative. Our study has provided important insight into the relationship between social integration and women's perceived access to DV support. Our findings underscore the heightened difficulties that socially isolated women face in identifying potential sources of support. As such, they suggest the importance of prevention policy that focuses on strengthening women's ties to others in their communities.

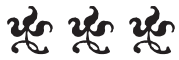

Authors' Note All of the material contained here was obtained with the informed consent of all participants. The analysis of the data and all conclusions and recommendations are the responsibility of the principal investigator/lead author and do not represent the opinions of either the U.S. National Science Foundation, The Nunatsiavut Government, the Nunatsiavut Research Committee, or City University of New York. K. Dombrowski remains solely responsible for the full content of this work.

Acknowledgments Special thanks to Fran Williams, Jane Dicker, Toby Pijogge, and Eva Lampe in Nain and to Jeffrey Smith for commentary, support, and help in this project.

Conflicting Interests The authors declared no potential conflicts of interest with respect to the research, authorship, and/or publication of this article.

Funding This project was supported by a grant from the U.S. National Science Foundation, Office of Polar Programs, Division of Arctic Social Sciences, GR ARC 0908155, with the approval of the Nunatsiavut Research Committee. Support for the analyses discussed here were received from the U.S. National Science Foundation, Social Behavioral and Economic Sciences Division, Office of Multidisciplinary Activities (SMA 1461132, and by the National Institutes of Health, National Institute of General Medicine (Ro1 GM118427).

\section{Notes}

1. Country food refers to foodstuffs collected through traditional subsistence activities (author citation, 2013)

2. The sibling relationship is both socially and genetically constructed as such sibling ties are usually but not always reciprocated. 


\section{References}

Anderson, K. M., Renner, L. M., \& Bloom, T. S. (2014). Rural women's strategic responses to intimate partner violence. Health Care for Women International, $35,423-441$.

Barrett, B. J., \& St. Pierre, M. (2011). Variations in women's help seeking in response to intimate partner violence: Findings from a Canadian populationbased study. Violence Against Women, 17, 47-70.

Belknap, J., Melton, H. C., Denney, J. T., Fleury-Steiner, R. E., \& Sullivan, C. M. (2009). The levels and roles of social and institutional support reported by survivors of intimate partner abuse. Feminist Criminology, 4, 377-402.

Berkman, L. F., Glass, T., Brissette, I., \& Seeman, T. E. (2000). From social integration to health: Durkheim in the new millennium. Social Science \& Medicine, 51, 843-857.

Bosch, K., \& Bergen, B. (2006). The influence of supportive and nonsupportive persons in helping rural women in abusive partner relationships become free from abuse. Journal of Family Violence, 21, 311-320.

Bosch, K., \& Schumm, W. R. (2004). Accessibility to resources: Helping rural women in abusive partner relationships become free from abuse. Journal of Sex \& Marital Therapy, 30, 357-370.

Brice-Bennett, C. (1977). Our footprints are everywhere: Inuit land use and occupancy in Labrador. Nain, Nfld.: Labrador Inuit Association.

Brownridge, D. A. (2008). Understanding the elevated risk of partner violence against Aboriginal women: A comparison of two nationally representative surveys of Canada. Journal of Family Violence, 23, 353-367.

Bryant-Davis, T., Chung, H., \& Tillman, S. (2009). From the margins to the center: Ethnic minority women and the mental health effects of sexual assault. Trauma, Violence, \& Abuse, 10, 330-357.

Bubar, R., \& Thurman, P. (2004). Violence against native women. Social Justice, 31, 70-86.

Burnette, C. (2015). From the ground up: Indigenous women's after violence experiences with the formal service system in the United States. The British Journal of Social Work, 45, 1526-1545.

Chester, B., Robin, R. W., Koss, M. P., Lopez, J., \& Goldman, D. (1994). Grandmother dishonored: Violence against women by male partners in American Indian communities. Violence and Victims, 9, 249-258.

Dombrowski, K. (2007). Subsistence livelihood, native identity and internal differentiation in Southeast Alaska. Anthropologica, 49, 211-229.

Dombrowski, K., Channell, E., Khan, B., Moses, J., \& Misshula, E. (2013). Out on the land: Income, subsistence activities, and food sharing networks in Nain, Labrador. Journal of Anthropology, 2013(1), 1-11.

Dombrowski, K., Habecker, P., Gauthier, G. R., Khan, B., \& Moses, J. (2016). Relocation Redux, Current Anthropology, 57, 785-805. 
Dombrowski, K., Khan, B., Moses, J., Channell, E., \& Dombrowski, N. (2014). Network sampling of social divisions in a rural Inuit community. Identities, 21, 134-151. doi:10.1080/1070289X.2013.854718

El-Bassel, N., Gilbert, L., Rajah, V., Folleno, A., \& Frye, V. (2001). Social support among women in methadone treatment who experience partner violence: Isolation and male controlling behavior. Violence Against Women, 7, 246-274.

Foran, H. M., \& O’Leary, K.D. (2008). Alcohol and intimate partner violence: A meta-analytic review. Clinical Psychology Review, 28, 1222-1234.

Ford-Gilboe, M., Varcoe, C., Noh, M., Wuest, J., Hammerton, J., Alhalal, E., \& Burnett, C. (2015). Patterns and predictors of service use among women who have separated from an abusive partner. Journal of Family Violence, 30, 419-431.

Goldsmith, D. J., \& Albrecht, T. L. (2011). Social support, social networks, and health. In T. L. Thompson, R. Parrott, \& J. F. Nussbaum (Eds.), The Routledge handbook of health communication (pp. 335-348). New York, NY: Routledge.

Greenfield, L., \& Smith, S. (1999). American Indians and crime. Washington, DC: U.S. Department of Justice Programs, Bureau of Justice Statistics, U.S. Government Printing.

Grossman, S. F., Hinkley, S., Kawalski, A., \& Margrave, C. (2005). Rural versus urban victims of violence: The interplay of race and region. Journal of Family Violence, 20, 71-81.

Hamby, S. (2000). The importance of community in a feminist analysis of domestic violence among American Indians. American Journal of Community Psychology, 28, 649-669.

Heckathorn, D. D. (2002). Respondent-driven sampling II: Deriving valid population estimates from chain-referral samples of hidden populations. Social Problems, 49, 11-34.

Hollenshead, J. H., Dai, Y., Ragsdale, M. K., Massey, E., \& Scott, R. (2006). Relationship between two types of help seeking behavior in domestic violence victims. Journal of Family Violence, 21, 271-279.

Jones, L. (2008). The distinctive characteristics and needs of domestic violence victims in a Native American community. Journal of Family Violence, 23, 113-118.

Kaukinen, C. (2004). The help-seeking strategies of female violent-crime victims: The direct conditional effects of race and the victim-offender relationship. Journal of Interpersonal Violence, 19, 967-990.

Kaukinen, C., Meyer, S., \& Akers, C. (2013). Status compatibility and helpseeking behaviors among female intimate partner violence victims. Journal of Interpersonal Violence, 28, 577-601.

Kirmayer, L. J. (2004). The cultural diversity of healing: Meaning, metaphor and mechanism. British Medical Bulletin, 69, 33-48.

Leonard, K. E., Kearns, J., \& Mudar, P. (2000). Peer networks among heavy, regular and infrequent drinkers prior to marriage. Journal of Studies on Alcohol, 61, 669-673. 
Luke, D. A., \& Harris, J. K. (2007). Network analysis in public health: History, methods, and applications. Annual Review of Public Health, 28, 69-93.

Matamonasa-Bennet, A. (2014). "A disease of the outside people": Native American men's perceptions of intimate partner violence. Psychology of Women Quarterly, 39, 20-36.

McEachern, D., Van Winkle, M., \& Steiner, S. (1998). Domestic violence among the Navajo: A legacy of colonization. Journal of Poverty, 2(4), 31-46.

Merli, M. G., Moody, J., Mendelsohn, J., \& Gauthier, R. (2015). Sexual mixing in Shanghai: Are heterosexual contact patterns compatible with an HIV/AIDS epidemic? Demography, 52, 919-942.

Meyer, S. (2010). Seeking help to protect the children? The influence of children on women's decisions to seek help when experiencing intimate partner violence. Journal of Family Violence, 25, 713-725.

Mitchell, R., \& Hodson, C. A. (1983). Coping with domestic violence: Social support and psychological health among battered women. American Journal of Community Psychology, 11, 629-654.

Moffitt, P., Fikowski, H., Mauricio, M., \& Mackenzie, A. (2013). Intimate partner violence in the Canadian territorial north: Perspectives from a literature review and a media watch. International Journal of Circumpolar Health, 72, 1-7.

Ruback, R. B., \& Jasmin, J. K. (1994). The more (men), the less merry: Social density, social burden, and social support. Sex Roles, 30, 743-763.

Seale, J. P., Shellenberger, S., \& Spence, J. (2006). Alcohol problems in Alaska Natives: Lessons from the Inuit. American Indian Alaska Native Mental Health Research Online, 13, 1-31.

Stark, E., \& Flitcraft, A. (1996). Women at risk: Domestic violence and women's health. Thousand Oaks, CA: SAGE.

Tan, C., Basta, J., Sullivan, C., \& Davidson, W. (1995). The role of social support in the lives of women exiting domestic violence shelters. Journal of Interpersonal Violence, 10, 437-451.

Thurston, L. (1996). Support systems for rural families: Rationale, strategies, and examples. Human Services in the Rural Environment, 20, 19-26.

Tjaden, P., \& Thoennes, N. (2000). Extent, nature, and consequences of intimate partner violence. Washington, DC: U.S. Department of Justice, National Institute of Justice.

Trujillo, M. P., \& Ross, S. (2008). Police response to domestic violence: Making decisions about risk and risk management. Journal of Interpersonal Violence, $23,454-473$.

Websdale, N. (1995). An ethnographic assessment of the policing of domestic violence in rural eastern Kentucky. Social Justice, 22, 102-123. Websdale, N. (1998). Rural women battering and the justice system. Thousand Oaks, CA: SAGE.

Whitbeck, L., Chen, X., Hoyt, D., \& Adams, G. (2004). Discrimination, historical loss, and enculturation: Culturally specific risk and resiliency factors for alcohol abuse among American Indians. Journal of Alcohol Studies, 65, 409-418. 
Wood, D. S., \& Gruenewald, P. J. (2006). Local alcohol prohibition, police presence and serious injury in isolated Alaska Native villages. Addiction, 101, 393-403.

Yuan, N. P., Koss, M. P., Polacca, M., \& Goldman, D. (2006). Risk factors for physical assault and rape among six Native American tribes. Journal of Interpersonal Violence, 21, 1566-1590.

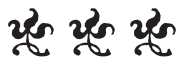

\section{Author Biographies}

G. Robin Gauthier is an assistant professor in the Department of Sociology at the University of Nebraska-Lincoln (UNL). She uses social network analysis to represent and understand how multiple facets of social life intersect to influence the experience of family and gender.

Sara C. Francisco graduated from Mount Holyoke College and studied Mathematics and History. She attends Pennsylvania State University studying sociology as a graduate student.

Bilal Khan is Happold professor of sociology at UNL and faculty affiliate at the Research, Evaluation \& Analysis for Community Health (REACH) Lab. He develops new analytic techniques and data-driven mathematical models to describe the emergence and propagation of behaviors and pathogens. He also directs the social networks research group (SNRG) Lab, a computational social science program that works closely with REACH on projects in Puerto Rico, New York, and Alaska.

Kirk Dombrowski is the John Bruhn professor of sociology and principal investigator (PI) of the REACH Lab at the UNL. He was originally trained as an anthropologist with a dissertation on the impact of Alaska Native land claims. For the last decade, however, he has worked on social networks and health. This work seeks to find better ways to understand social inequalities, including health disparities in Inuit and Alaska Native communities, and HIV/HepC transmission among rural drug users in Puerto Rico and the Midwest. He also serves as director of the Minority Health Disparities Initiative at UNL. 